\title{
PERSEPSI MASYARAKAT TERHADAP PENGELOLAAN TAMAN WISATA ALAM TELAGA WARNA KABUPATEN BOGOR, PROVINSI JAWA BARAT
}

\section{Community Perception of Management Telaga Warna Natural Tourism Park Bogor District, West Java Province}

\author{
Elka Pebriyandi Suherlan ${ }^{1}$, Messalina L. Salampessy ${ }^{2}$ dan Abdul Rahman Rusli ${ }^{3}$ \\ ${ }^{1}$ Direktorat Pemolaan dan Informasi Konservasi Alam, Direktorat Jenderal KSDAE, KLHK \\ Jl. Ir. H. Juanda No. 1912, Bogor \\ e-mail : elkapebriyandi9@gmail.com \\ ${ }^{2}$ Fakultas Kehutanan, Universitas Nusa Bangsa \\ J1. KH. Sholeh Iskandar KM. 4 Tanah Sereal - Bogor 16166, Indonesia \\ e-mail : meisforester76@gmail.com \\ ${ }^{2,3}$ Fakultas Kehutanan, Universitas Nusa Bangsa \\ J1. KH. Sholeh Iskandar KM. 4 Tanah Sereal - Bogor 16166, Indonesia \\ e-mail : rusli.abdulrahman@yahoo.co.id
}

Corespondent author : meisforester76@gmail.com

\begin{abstract}
The existency of conservation areas and surrounding communities is an inseparable part. The interaction of the people with the forest area is influenced by the perception of local community surrounding the forest. This study was aimed to describe the community's knowledge about the Nature Tourism Park (NTP) and community perceptions of the management of NTP. This research was conducted in May - June 2020 in Tugu Utara Village, Cisarua District, Bogor. Data obtained through field observations, interviews, questionnaires and literature studies, and were analyzed quantitatively by describing the percentage of people's understanding of the management of NTP. The results show that the community has high knowledge of the NTP concept, function and role of NTP, NTP management and community participation in NTP management and the community has a good level of understanding about the existence and role and function of NTP for the community, a good understanding of the active role of the community. in the management of TWA and the importance of building cooperation in the management of NTP. Therefore, it is necessary to make efforts to increase the role and participation of the local community in the effort to utilize the potential of the area and its preservation.
\end{abstract}

Keywords: Community, Tourism Park, Perception

\begin{abstract}
ABSTRAK
Keberadaan kawasan konservasi dan masyarakat sekitar merupakan bagian yang tidak terpisahkan. Interaksi dari Masyarakat dengan kawasan hutan dipengaruhi oleh persepsi masyarakat tentang hutan itu sendiri. Penelitian ini bertujuan untuk menguraikan pengetahuan masyarakat terhadap Taman Wisata alam (TWA) dan persepsi masyarakat terhadap pengelolaan TWA. Penelitian ini telah lakukan pada bulan Mei - Juni 2020 di Desa Tugu Utara Kecamatan Cisarua Bogor. Data diperoleh melalui observasi lapangan, wawancara, kuisioner dan studi pustaka kemudian dianalisis secara kualitatif dengan menguraikan prosentase terbanyak pemahaman masyarakat terhadap pengelolaan TWA. Hasil menunjukkan bahwa masyarakat memiliki pengetahuan yang tinggi terhadap konsep TWA, fungsi dan peran TWA, pihak pengelola TWA dan pemanfaatan sumberdaya kawasan oleh masyarakat. Masyarakat memiliki persespsi yang baik tentang keberadaan dan peran serta fungsi TWA bagi masyarakat. Selain itu pemahaman yang baik tentang peran aktif masyarakat dalam pengelolaan TWA dan pentingnya membangun kerjasama dalam pengelolaan TWA. Oleh karena itu, perlu dilakukan upaya-upaya meningkatkan bentuk peran dan partsipasi masyarakat setempat bagi upaya pemanfaatan potensi kawasan dan kelestariannya.
\end{abstract}

Kata kunci: Masyarakat, Persepsi, Taman Wisata Alam 


\section{PENDAHULUAN}

Kawasan konservasi merupakan salah satu fungsi penting dari suatu ekosistem hutan. Pengelolaan hutan ini tidak hanya berfungsi dari aspek ekologis namun memiliki fungsi lain yang saling menunjang yaitu fungsi budaya, sosial, dan ekonomi bagi masyarakat di sekitarnya. Undang-Undang Nomor 41 tahun 1999 menyebutkan bahwa hutan konservasi meliputi Kawasan Suaka Alam, Kawasan Pelestarian Alam, dan Taman Buru. Hal ini diperjelas lagi pada UndangUndang Nomor 5 tahun 1990 bahwa Kawasan Suaka Alam terdiri dari Cagar Alam dan Suaka Margasatwa, sedangkan Kawasan Pelestarian Plam terdiri dari Taman Nasional, Taman Hutan Raya, dan Taman Wisata Alam.

Taman Wisata Alam (TWA) Telaga Warna merupakan salah satu kawasan konservasi di Jawa Barat dengan potensi ekosistem dan wisata yang terus mengalami perkembangan dalam pengelolaannya. Keberadaan masyarakat desa sekitar kawasan TWA turut mempengaruhi upaya pengelolaannya. Pada beberapa tahun terakhir, upaya pengelolaan cenderung mengalami permasalahan mengenai akses masyarakat dalam pemanfaatan sumber daya alam. Permasalahan ini merupakan akibat dari peralihan fungsi Kawasan Hutan Lindung menjadi Kawasan Suaka Alam dan Kawasan Pelestarian Alam. Peralihan fungsi tersebut memberi dampak pada pembatasan aktifitas bagi masyarakat dalam memanfaatkan sumber daya alam.

Pengelolaan kawasan konservasi dan peran aktif masyarakat merupakan bagain yang tidak dapat dipisahkan. Perilaku masyarakat sekitar kawasan sangat dipegaruhi oleh persepsi mereka terhadap kawasan hutan.

Persepsi didefinisikan sebagai proses yang menyangkut masuknya pesan atau informasi ke dalam otak manusia. Persepsi ini merupakan keadaan yang menyatu dari individu terhadap stimulus yang diterimanya. Pikiran, perasaan, pengalaman-pengalaman individu yang akan ikut aktif berpengaruh dalam proses persepsi (Mempun, 2013).

Pada proses persepsi, individu dituntut untuk memberikan pemahaman bersifat positif, negatif, dan sebagainya. Apabila masyarakat memiliki persepsi positif mengenai keberadaan hutan di sekitarnya, maka akan memberikan implikasi positif. Demikian pula sebaliknya, apabila masyarakat presepsi negatif maka tindakan yang akan dihasilkannya cenderung merusak atau merugikan kelestarian hutan. Dukungan masyarakat dalam pengelolaan kawasan konservasi sangat diperlukan demi menjaga kelestarian kawasan hutan ini (Daulay dan Hidayat, 2017).

Persepsi masyarakat akan mengakomodasi upaya meningkatkan peran dan partisipasi masyarakat dalam pengelolaan kawasan. Untuk itulah penelitian ini penting dilakukan.

\section{METODE PENELITIAN}

Penelitian ini dilaksanakan di TWA Telaga Warna, Desa Tugu, Cisarua, Kabupaten Bogor, Provinsi Jawa Barat. Waktu penelitian dilaksanakan pada Mei Juli 2020.

Desa Tugu utara adalah salah satu desa yang terletak di sekitar kawasan hutan Taman wisata alam Telaga Warna tepatnya pada Kecamatan Cisarua. Jarak Desa Tugu utara dari ibukota Kabupaten Bogor $\pm 44 \mathrm{Km}$. Luas Desa Tugu Utara sekitar 1.703 Ha.

Secara geografis, Desa Tugu Utara berbatasan dengan Kecamatan Sukamakmur di Sebelah Utara, Kecamatan Pacet Cianjur di sebelah timur, Desa Tugu Selatan di sebelah selatan, dan Desa Batu Layang di sebelah barat. Kondisi topografi yang berada pada ketinggian 650-1200 m dpl.

Penduduk Desa Tugu Utara pada Tahun 2019 berjumlah 10.291 jiwa. Jumlah kepala keluarga di Desa Tugu Utara sejumlah 3.078 KK. Mata pencaharian penduduk didominasi sebagai buruh perkebunan dan petani. 
Penelitian ini merupakan penelitian deskriptif dengan pendekatan kualitatif. Pengumpulan data dilakukan melalui kegiatan observasi, wawancara (interview) dan kunjungan ke instansi terkait, serta studi literatur.

Penentuan responden dilakukan dengan metode purposive sampling. Purposive sampling dilakukan dengan menentukan kriteria terhadap responden terpilih yaitu masyarakat dengan aktifitas keseharian yang berhubungan dengan kawasan dan berdomisili lebih dari 5 tahun. Jumlah responden yang diambil sebanyak 33 orang. Responden terdiri dari perangkat desa, tokoh masyarakat/agama, dan anggota masyarakat. Data persepsi yang diperoleh ditabulasikan sehingga dapat diketahui frekuensi dan persentasenya. Selanjutnya, data dianalisis secara deskriptif.

\section{HASIL DAN PEMBAHASAN}

\section{A. Karakteristik Masyarakat}

Kelompok dominan umur responden merupakan usia produktif. Hal tersebut dapat dilihat berdasarkan data kelompok umur. Kelompok umur 46-55 tahun (43\%), kelompok umur 36-45 tahun (34\%) dan 25-35 tahun (23\%). Berdasarkan jenis kelamin responden, $83,3 \%$ berjenis kelamin laki-laki dan $16,7 \%$ berjenis kelamin perempuan.

Tingkat Pendidikan masyarakat didominasi pada tingkat pendidikan SMA (57\%). Pekerjaan mayoritas adalah sebagai buruh kebun teh $(56 \%)$ dengan penghasilan sebagian masyarakatnya berada pada kisaran Rp. 1.000 .000 - Rp. 2.000.000.

Tingkat pendidikan masyarakat yang umumnya adalah SMA cukup memudahkan pemahaman masyarakat dalam meningkatkan peran dalam pengelolaan kawasan.

\section{Pengetahuan Masyarakat tentang TWA}

1. Pengetahuan tentang TWA Telaga Warna

Pengetahuan masyarakat tentang TWA memperlihatkan pemahaman yang tinggi
$(66,7 \%)$ dimana masyarakat memahami bahwa TWA merupakan kawasan yang dilindungi, dilestarikan. Dengan demikian masyarakat dapat dikategorikan sudah memahami bahwa pemanfaatan potensi TWA perlu disesuaikan dengan peran dan fungsinya (Gambar 1).

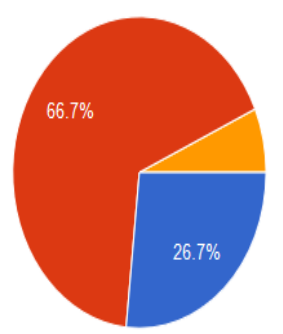

Wilayah konservasi yang memiliki peruntukan sebagai pariwisata maupu - Kawasan yang harus dilindungi, dilestarikan, dan dimanfaatkan secara. Kawasan hutan konservasi yang dapat dimanfaatkan untuk kegiatan pariwisat. Kawasan yang cukup luas untuk menjamin kelestarian potensi dan day. - Kawasan yang kondisi alamnya relatife masih utuh.

Gambar 1. Tingkat pengetahuan masyarakat terhadap nilai penting TWA Telaga Warna

2. Pengetahuan tentang Fungsi dan Peran TWA

Pengetahuan masyarakat terhadap fungsi dan peran TWA dalam katagori tinggi $(66,7 \%)$. Hal tersebut menjelaskan bahwa masyarakat memahami fungsi dan peran TWA sebagai kawasan yang dapat memberikan konstribusi ekologi dan ekonomi bagi masyarakat setempat (Gambar 2).

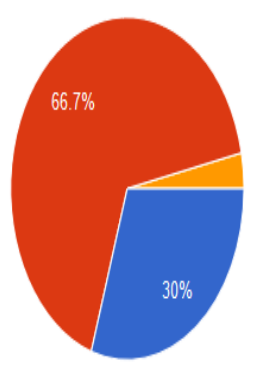

- Tempat pariwisata, rekreasi, pelindung system penyangga kehidupan bagi da.

- Kawasan yang pemanfaatannya dapat memberikan konstribusi ekonomi kepa.

Kawasan yang mempunyai bilai komersial dalam pembangunan nya.

Kawasan yang menjaga kelestarian flora dan fauna di dalamnya.

- Kawasan yang bisa dimanfaatkan oleh masyarakat tanpa melihat aturan yang.

Gambar 2. Fungsi dan Peran TWA Telaga Warna

3. Pengetahuan tentang Pengelola TWA.

Pengetahuan masyarakat tentang pengelola kegiatan di TWA termasuk dalam kategori tinggi $(63,3 \%)$. Kondisi tersebut memperlihatkan pemahaman masyarakat 
bahwa pengelola kawasan ini adalah Balai Besar KSDA Jawa Barat dan Pemerintah desa setempat (Gambar 3).
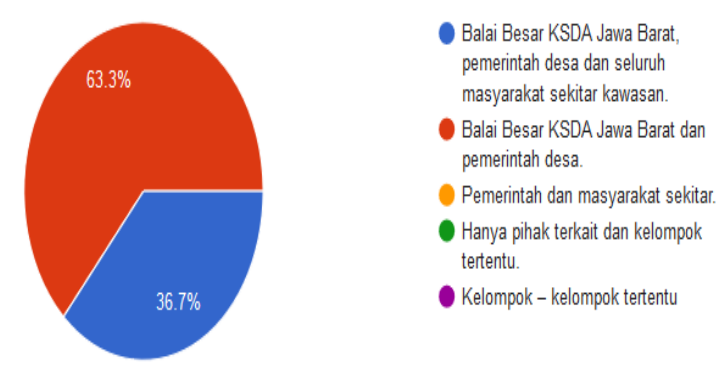

Gambar 3. Pengelola Kegiatan di TWA Telaga Warna

4. Pengetahuan tentang Peran serta masyarakat dalam pengelolaan TWA.

Pengetahuan masyarakat tentang peran masyarakat dalam pengelolaan TWA masuk pada katagori tinggi $(66,7 \%)$. Sudah terbentuk pemahaman bahwa masyarakat perlu berperan serta dalam menjaga perlindungan, pelestarian dan pemanfaatan di kawasan TWA. Bentuk peran serta masyarakat adalah sebagai volunteer/sukarelawan untuk melakukan penanaman kembali untuk mencegah terjadinya longsor, sebagai pemetik teh dan sebagai tenaga kerja di sekitar lokasi wisata alam.
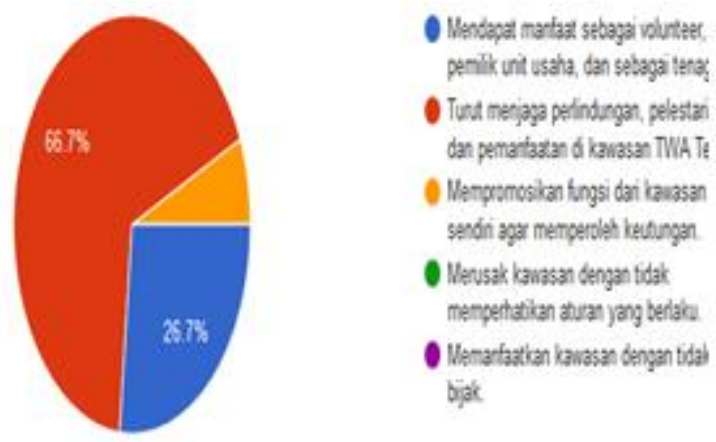

Gambar 4. Peran Masyarakat di sekitar TWA

5. Pengetahuan tentang pemanfaatan sumberdaya kawasan oleh masyarakat.

Pengetahuan masyarakat tentang pemanfaatan sumberdaya kawasan oleh masyarakat berada pada katagori tinggi
$(63,3 \%)$. Hal ini menjelaskan bahwa kegiatan pemanfaatan sumberdaya kawasan dibatasi pada aturan tertentu mengingat kawasan ini merupakan kawasan konservasi (Gambar 5).

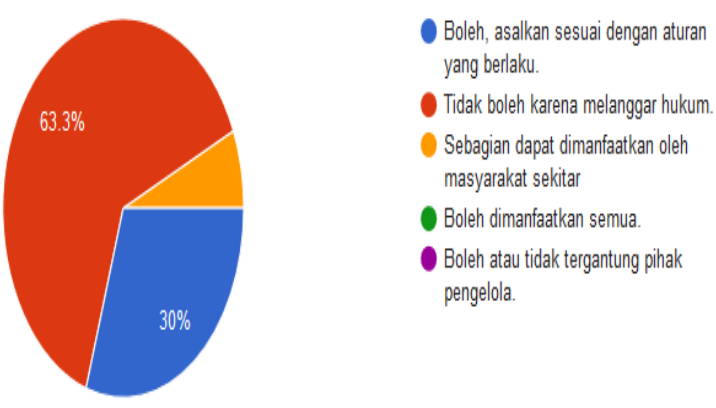

Gambar 5. Tidak boleh karena melanggar hukum

6. Persepsi Masyarakat terhadap Pengelolaan Kawasan TWA

Berdasarkan hasil penelitian persepsi masyarakat terhadap Pengelolaan Kawasan TWA Telaga Warna dapat diuraikan pada Tabel 1 sebagai berikut:

Tabel 1. Pemahaman Masyarakat terhadap TWA

\begin{tabular}{|c|c|c|}
\hline No. & Pemahaman terhadap TWA & Keterangan \\
\hline 1 & $\begin{array}{l}\text { Potensi flora dan fauna perlu } \\
\text { dilestarikanndan dan } \\
\text { dimanfaatkan untuk kegiatan } \\
\text { wisata }\end{array}$ & Paham \\
\hline 2 & \begin{tabular}{lcr} 
Peran penting & TWA terhadap \\
ekonomi & \multicolumn{2}{c}{ masyarakat, } \\
pengaturan & akses & dan \\
pemanfaatan & TWA & oleh \\
masyarakat & &
\end{tabular} & Paham \\
\hline 3 & $\begin{array}{l}\begin{array}{l}\text { Pelibatan dan peran aktif } \\
\text { masyarakat }\end{array} \\
\text { pemanfaatan hasil } \\
\text { dalam } \\
\text { butan kayu }(\mathrm{HHBK})\end{array}$ & Paham \\
\hline 4 & $\begin{array}{l}\text { Pelibatan masyarakat dalam } \\
\text { pengelolaan kawasan dan } \\
\text { promosi wisata }\end{array}$ & Paham \\
\hline
\end{tabular}

\section{PEMBAHASAN}

Pengetahuan masyarakat tentang keberadaan TWA Telaga Warna serta fungsi dan perannya tergolong paham. Hal ini dilatarbelakangi oleh tingkat pendidikan masyarakat yang cukup tinggi. Keberhasilan 
pengelolaan sangat ditunjang dengan pemahaman yang baik dari masyarakat tentang fungsi dan peran taman wisata serta secara tidak langsung mempengaruhi peran partisipasi masyarakat pada pengelolaan kawasan tersebut (Wahyuni dan Mamonto, 2012).

Dengan melihat aspek pekerjaan masyarakat setempat yang didominasi sebagai petani dan buruh perkebunan, hal ini sejalan yang disampaikan oleh Wahyuni \& Mamonto (2012), yang menunjukkan bahwa penduduk desa yang berada di sekitar kawasan konservasi mayoritas bekerja sebagai petani dan buruh tani.

Masyarakat sangat memerlukan peningkatan pengetahuan melalui kegiatan penyuluhan dan peningkatan peran serta dalam pengelolaan kawasan. Hal ini, sejalan dengan yang disampaikan Sadono et al. (2013) bahwa penetapan masyarakat sebagai subjek pembangunan kehutanan penting di laksanakan. Dengan demikian masyarakat akan aktif berperan mulai dari perencanaan, pelaksanaan, hingga monitoring dan evaluasi. Untuk itulah peningkatan peran serta masyarakat perlu diinisiasi oleh pengelola kawasan. Suyono, Harahap, and Aththorick (2017) menjelaskan bahwa peran aktif masyarakat akan berkembang apabila semakin banyak manfaat yang diperolehnya mengingat tingginya ketergantungan masyarakat pada terhadap kawasan itu.

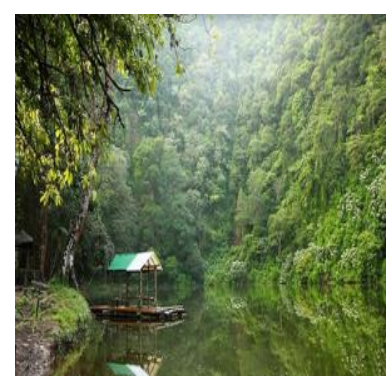

(a)

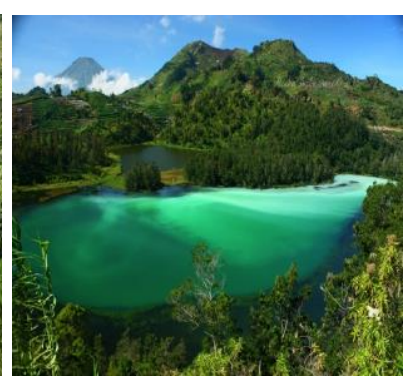

(b)
Sumber : Informasi Kawasan Konservasi lingkup BBKSDA Jabar, 2016.

Gambar 6 . (a). Sumber air TWA Telaga Warna, (b) Telaga Warna
Menurut Peraturan Menteri Lingkungan Hidup dan Kehutanan No.76/MenlhkSetjen/2015 tentang Kriteria Zona Pengelolaan Taman Nasional Dan Blok Pengelolaan Cagar Alam, Suaka Margasatwa, Taman Hutan Raya Dan Taman Wisata Alam menyatakan bahwa kewenangan dalam sistem pengelolaan di TWA Telaga Warna adalah Balai Besar Konservasi Sumber Daya Alam (BBKSDA) Jawa Barat. Lebih spesifiknya, bagian yang mengurusi TWA Telaga Warna adalah seksi Wilayah 2, Bidang Konservasi Wilayah 1 Bogor. Peran kewenangan ini telah dipahami baik oleh masyarakat. Peran masyarakat dalam pengelolaan adalah memiliki tanggung jawab dalam upaya menjaga kelestarian Kawasan karena keberadaan kawasan itu sendiri sangat bermanfaat bagi mereka. Selain kebutuhan air sehari-hari masyarakat yang terpenuhi dari cadangan air Telaga Warna, keberadaan kawasan ini juga turut meningkatkan perekonomian masyarakat setempat.

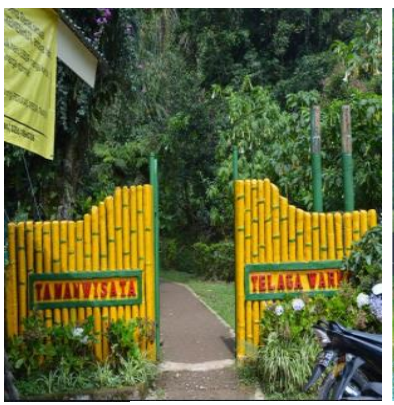

(a)

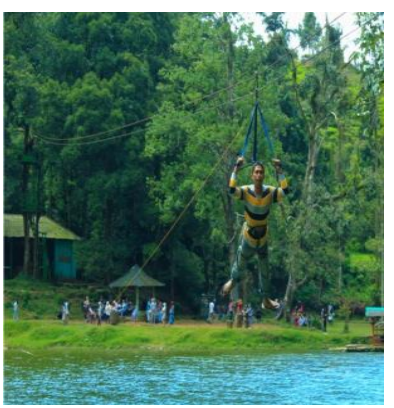

(b)
Sumber : Informasi Kawasan Konservasi lingkup BBKSDA Jabar, 2016.

Gambar 7. (a). Pintu masuk TWA Telaga Warna (b). Wahana wisata (flying fox)

Masyarakat telah memilki pemahaman yang baik bahwa TWA adalah sebagai Taman wisata yang memiliki berbagai potensi flora dan fauna, yang perlu dilestarikan dan salah satu potensinya adalah pengembangan kegiatan wisata. Hal ini sejalan dengan (Setiawan, et al 2017) bahwa dengan mengetahui persepsi dan sikap masyarakat terhadap sumber daya alam setempat akan lebih memudahkan keterlibatan masyarakat 
untuk bersama pengelola merancang strategi konservasi dan manajemen yang efektif agar sumber daya alam tetap lestari dan dapat meningkatkan kesejahteraan masyarakat tersebut.

Masyarakat cukup memahami bahwa kawasan ini dapat membantu perekonomiannya dan pengelola perlu mengatur akses pemanfaatan tersebut. Masyarakat mempunyai kesadaran untuk ikut mengelola kawasan konservasi, karena kawasan konservasi ini terutama sangat membantu ketersediaan sumber air dan berbagai sumberdaya alam yang dapat dimanfaatkan oleh masyarakat.

Masyarakat memahami bahwa dalam pengelolaan kawasan konservasi ini, ada peraturan tentang larangan bagi siapapun mencabut atau merusak tanaman, serta melakukan perburuan atau memberi makan binatang-binatang yang berada di wilayah ini. Masyarakat wajib mengajukan ijin dari pengelola untuk mendapatkan akses pemanfaatan sumberdaya alam di TWA Telaga warna. Proses ijin yang dilakukan masyarakat dengan cara mengajukan hak pengelolaan kepada BBKSDA Jawa Barat dan pemerintah, untuk selanjutnya diproses dan jika sudah disetujui, maka masyarakat berhak untuk mengelola dan dapat mengambil manfaat dari sumberdaya alam yang tersedia sesuai aturan yang berlaku.

Masyarakat telah memiliki pemahaman bahwa pentingnya berperan aktif terutama dalam kegiatan pengelolaan HHBK. Oleh pengelola aktifitas ini masyarakat diijinkan memanfaatan lahan-lahan kosong dengan penanaman Rumput Gajah (Pennisetum purpureum) terutama pada lahan-lahan kosong yang terletak pada bagian terluar dari areal konservasi serta penanaman berupa tanaman Macadamia (Macadamia integrifolia) dan Papaya (Carica papaya L). Jenis Flora di TWA Telaga Warna adalah Rasamala (Altingia excels), Puspa (Scima wallichii), Saninten (Castanopsis argentea), Pasang (Quercus sp), Huru (Litsea sp),
Beleketebe (Sloanea sigun), Kiaksara (Macodes petola) dan jenis - jenis jamur.

Masyarakat telah memahami dengan baik, bahwa pentingnya kerjasama dalam pengelolaan kawasan ini. Hasil observasi memperlihatkan bahwa pengelolaan TWA Telaga Warna dilaksanakan bersama oleh BBKSDA Jawa Barat dengan masyarakat sekitar. Setiap usaha pengembangan TWA Telaga Warna merupakan hasil kesepakatan Bersama. Masyarakat memiliki keinginan untuk terus dapat melestarikan Situ Telaga Warna agar tetap indah. Sebagai contoh masyarakat mendukung inisiatif kegiatan wisata serta masyarakat turut berperan meningkatkan promosi bagi kunjungan wisatawan ke lokasi ini, beberapa berperan sebagai pemandu wisata. Selain itu, masyarakat mendukung pengelola dalam membantu kegiatan konservasi terutama kegiatan monitoring Burung Elang Jawa (Nizaetus bartelsi) setiap tahun dimana masyarakat berperan aktif pada kegiatan ini.

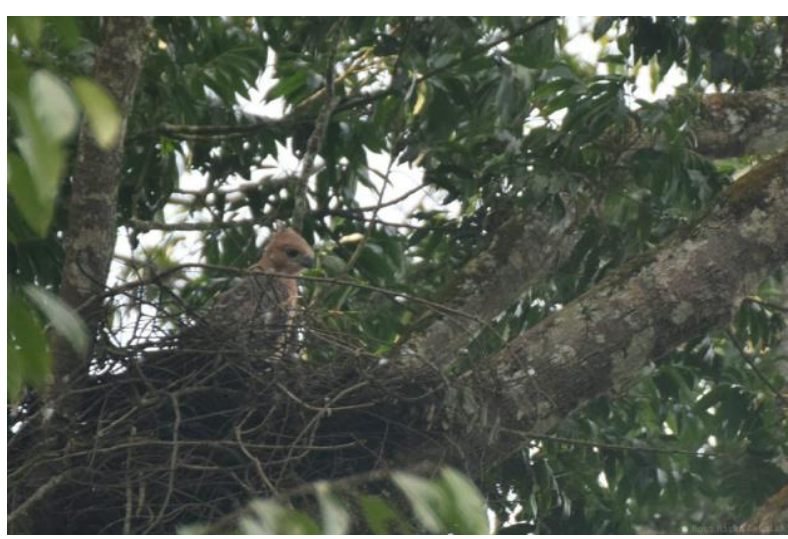

Sumber : Balai Besar Taman Nasional Gunung Gede Pangrango Narasi dan Foto: Robi Rizki Zatnika, A.Md. - PEH Balai Besar TNGGP Cibodas, 17 Juli 2018.

Gambar 8 . Burung Elang Jawa (Nisaetus bartelsi)

Masyarakat dan pengelola telah memiliki pemahaman yang baik tentang pentingnya pelibatan tokoh masyarakat serta berbagai pihak dalam pengelolaan kawasan ini. Pengelola Kawasan dan masyarakat secara aktif perlu bekerjasama dalam upaya kegiatan konservasi di dalam kawasan maupun di 
sekitar kawasan. Jika kawasan yang dilindungi dianggap masyarakat sebagai penghalang aktifitasnya maka ada kecenderungan masyarakat setempat akan menggagalkan upaya pelestariannya.

Pelibatan pemangku adat, tokoh masyarakat diperlukan dalam kegiatan konservasi kawasan. Pemerintah perlu memastikan bahwa upaya menerapkan model pengelolaan kolaboratif tidak hanya berhenti sampai pada tingkat lokal tapi perlu dirasakan oleh seluruh komponen masyarakat. Sehingga meminalisir potensi konflik sosial yang muncul di dalam masyarakat (Peranginangin, 2014). Masyarakat sebaiknya jangan diberikan peran sebagai penjaga hutan, namun perlu ditingkatkan peran dalam perencanaan hingga monitoring dan evaluasi kegiatan sehingga merasakan atau menikmati hasil hutan tersebut dengan lebih maksimal. Sejalan yang disampaikan oleh Sumarto (2009) bahwa partisipasi memiliki makna sebagai proses baik individu, kelompok sosial dan organisasi yang ada, mengambil peran dan ikut memengaruhi proses perencanaan, pelaksanaan, dan pemantauan kebijakankebijakan yang ada.

Pengelola dan masyarakat telah memahami baik bahwa pentingnya pelibatan berbagai pihak dalam pengelolaan kawasan ini. Pihak pengelola berkerjasama dengan desa Tugu utara untuk mempromosikan kawasan TWA Telaga Warna melalui berbagai cara (Spanduk, media sosial, dan leaflet). Melalui cara ini masyarakat memahami dengan baik dan lebih meningkatkan perannya bagi perlindungan kawasan.

Mitchell, et.al. (2000) menyatakan bahwa masyarakat dalam pengelolaan lingkungan dan sumber daya alam, dimungkinkan untuk terlibat aktif agar dapat memepoleh manfaat bersama. Manfaat tersebut antara lain dapat (1) merumuskan persoalan bersama dengan lebih efektif, (2) mendapatkan informasi dan pemahaman yang baik, (3) merumuskan alternatif penyelesaian masalah yang secara sosial akan dapat diterima dan (4) membentuk perasaan memiliki terhadap rencana dan penyelesaian. Dengan demikian akan memudahkan penerapan berbagai program yang dikembangkan. Sehingga diharapkan upaya bersama untuk kelestarian Kawasan dan peningkatan kesejahteraan masyarakat dapat tercapai.

\section{SIMPULAN DAN SARAN}

\section{A. SIMPULAN}

Pengetahuan dan Persepsi masyarakat Desa Tugu Utara terhadap keberadaan, peran dan fungsi Taman wisata alam Telaga Warna dapat dikategorikan ke dalam pengetahuan yang tinggi dan pemahaman yang baik. Dengan demikian dapat diartikan bahwa masyarakat menyadari keberadaaan dan fungsi kawasan TWA Telaga Warna penting untuk menopang daya dukung kelangsungan hidup masyarakat tersebut.

\section{B. SARAN}

Perlu dilakukan upaya-upaya meningkatkan bentuk peran dan partsipasi masyarakat setempat bagi upaya pemanfaatan potensi kawasan dan kelestariannya serta kesejahteraan masyarakat setempat.

\section{UCAPAN TERIMAKASIH}

Ucapan terima kasih disampaikan kepada pengelola TWA Telaga Warna dan masyarakat Desa Tugu Utara yang telah membantu penelitian terlaksana dengan baik.

\section{DAFTAR PUSTAKA}

Daulay.D.N.O, Hidayat.J.W, 2017 Persepsi Masyarakat terhadap Pengelolaan Taman nasional Batang Gadis, Kabupaten Mandailin Natal, Provinsi Sumatera Utara. Proceeding Biology Education Conference Volume 14, Nomor 1 Halaman 233-240 
Mempun, S. 2013. Persepsi dan Sikap Masyarakat Terhadap Kegiatan Kesatuan Pengelolaan Hutan Produksi (KPH-P) Model Dampelas Tinombo (Studi Kasus Desa Talaga Kecamatan Damsol Kabupaten Donggala). Skripsi. Fakultas Kehutanan Universitas Tadulako.

Mitchell,B., B. Setiawan., dan D.H. Rahmi., 2000. Pengelolaan Sumber Daya dan Lingkungan. Gadjah Mada University Press. Yogyakarta

Peranginangin.L.S.U,2014.Partisipasi Masyarakat dalam Pengelolaan Kawasan Konservasi. Jurnal Kebijakan \& Administrasi Publik JKAP Vol 18 No 1- Mei 2014.

Sadono, Yulian et al. 2013. "Peran Serta Masyarakat Dalam Pengelolaan Taman Nasional Gunung Merbabu Di Desa Jeruk Kecamatan Selo , Kabupaten Boyolali." Jurnal Pembangunan Wilayah dan Kota 9(1): 53-64.

Sumarto, Hetifah SJ. 2009. Inovasi, Partisipasi, dan Good governance 20 Prakarsa Inovatif dan Partisipatif di Indonesia. Yayasan Obor Indonesia. Jakarta
Setiawan, Heru, R Purwanti, and R Garsetiasih. 2017. "Persepsi Dan Sikap Masyarakat Terhadap Konservasi Ekosistem Mangrove Di Pulau Tanakeke Sulawesi Selatan." Jurnal Penelitian Sosial dan Ekonomi Kehutanan 14(1): 57-70.

Suyono, R. Hamdani Harahap, and T. Alief Aththorick. 2017. "Persepsi Masyarakat Desa Lae Hole Ii Dalam Pengelolaan Taman Wisata Alam (Twa) Sicike-Cike." Jurnal Jeumpa 4(1): 67-79.

Undang-Undang RI Nomor 41 Tahun 1999 tentang Kehutanan. Lembaran Negara RI Tahun 1999 No. 167. Jakarta, 30 September 1999.

Wahyuni, N. I, R. Mamonto. (2012). Persepsi Masyarakat terhadap Taman Nasional dan Sumber Daya Hutan: Studi Kasus Blok Aketawaje, Taman Nasional Aketawaje Lolobata. Info BPK Manado, 2(1), pp.1-16.

Undang-Undang Republik Indonesia Nomor 5 Tahun 1990 Tentang Konservasi Sumber Daya Alam Hayati

Ekosistemnya 